\title{
The Mental Foramen II: Radiographic Study of the Superior-Inferior Position, Appearance and Accessory Foramina in Iraqi Population
}

\author{
El Foramen Mental II: Estudio Radiográfico de la Posición Superior-inferior, \\ Aspecto y Forámenes Accesorios de una Población Iraquí
}

Mohammad H. Al-Shayyab*; Firas Alsoleihat**; Najla S. Dar-Odeh*; Soukaina Ryalat" \& Zaid H. Baqain****

\begin{abstract}
AL-SHAYYAB, M. H.; ALSOLEIHAT, F.; DAR-ODEH, N. S.; RYALAT, S. \& BAQAIN, Z. H. The mental foramen II: Radiographic study of the superior-inferior position, appearance and accessory foramina in Iraqi population. Int. J. Morphol., 34(1):310-319, 2016.

SUMMARY: Accurate information regarding the vertical location and appearance of the mental foramen, and the presence of accessory foramina, can have clinical significance, such as reducing complications that may occur during many oral surgical procedures involving the mental area. Geographic variations were reported in these variables. The aim was to evaluate the above-mentioned variables in an Iraqi sample. Five hundred eighteen panoramic radiographs of a random Iraqi sample $(257$ males, $261 \mathrm{females,} \mathrm{average} \mathrm{age=}$ 46.5 years) were evaluated with regard to the above-mentioned variables, as well as the symmetry of the foramen regarding these variables. The area below the apices of mandibular premolars, and the continuous type were the most frequent vertical location and appearance of the mental foramen, respectively. Age advancement was found to be associated with an increase in the frequency of more inferior positioning and continuous appearance. The vertical position and appearance were asymmetrical in $16.2 \%$ and $20.1 \%$ of cases, respectively. Symmetry in the vertical location was statistically significant between sexes $(\mathrm{P}=0.035)$, and young and old ages $(\mathrm{P}=0.000)$. Symmetry in the appearance was found statistically significant $(\mathrm{P}=0.025)$ only between the two age groups. Accessory foramina were recorded in $7.3 \%$ of cases. The most common vertical location and appearance of the mental foramen on panoramic radiographs in this group are below the apices of mandibular premolars, and continuous type, respectively. This is in consistence with the findings of previous studies on other populations. The mental foramen usually has symmetrical vertical location and appearance. Accessory foramina are recorded in a percentage lower than that recently reported in some regional countries.
\end{abstract}

KEY WORDS: Mental foramen; Panoramic radiographs; Geographic variation; Iraqi population.

\section{INTRODUCTION}

The mental foramen is located on the lateral surface of the mandible and represents the mesial termination of the inferior dental and mental canals. It is the foramen from which the inferior alveolar nerve and artery exit and then provide blood supply and innervations to the lower teeth, lip, gingiva and lower face mesial to the first molar area (Williams \& Bannister, 2000). Viewed from inside out, the mental foramen looks usually postero-superiorly (Haghanifar \& Rokouei, 2009).

The usual description of the vertical (superior-inferior) position of the foramen is below the apices of the closest teeth; above the lower margin of the mandible by about 13-15 mm (Haghanifar \& Rokouei). However, in- dividual variation could lead to other locations ranging from above to below the level of apices of mandibular premolars (Al-Khateeb et al., 2007). Additionally, the mental foramen on panoramic radiographs in relation to the mental canal commonly provides continuous appearance. However, other appearances have been reported in other individuals as diffused, separated or unidentified (Robinson et al., 2000; Al-Khateeb et al., 2007). It has recently been reported that these individual variations are present between populations of different geographies (Ari et al., 2005).

Studies using clinical radiographs or dried skulls of human mandible usually demonstrated a single

\footnotetext{
" Department of Oral and Maxillofacial Surgery, Oral Medicine and Periodontology, Faculty of Dentistry, The University of Jordan, Amman, Jordan.

** Department of Conservative Dentistry, Faculty of Dentistry, The University of Jordan, Amman, Jordan.

**** Dean, Department of Oral and Maxillofacial Surgery, Oral Medicine and Periodontology, Faculty of Dentistry, University of Jordan, Amman, Jordan.
} 
presentation of the mental foramen. However, it is rarely, with a prevalence ranging from 1.4 to $10 \%$, presented in a double or multiple fashion terming any additional foramen as accessory one (Cagirankaya \& Kansu, 2008). Furthermore, the mental foramen has been reported to be completely absent in some rare cases (de Freitas et al., 1979) and to exhibit a clear racial trend (Green, 1987; Santini \& Land, 1990).

Accurate information regarding the vertical location and appearance of mental foramen can have very important clinical significance. Accurately locating the vertical position of the mental foramen would help in achieving successful local anaesthesia and reducing the rate of neural and vascular complications in the mental region. This can be aided by an accurate placement of the needle's insertion point, modifying the flap design and vertical level of soft tissue incisions (Moiseiwitsch, 1998), osteotomy sites and extension of bony drilling. These may all be required in many surgical procedures such as osteotomy, implant surgery and other invasive surgical procedures involving the mental region (Phillips et al., 1990). The anatomy and other characteristics of mental foramen such as appearance and presence of accessory foramina could also be used in evaluating some morphological and paleoanthropologic features of the human mandible and of the facial skeleton in different populations (Hasan, 2010).

The vertical location of mental foramen and other characteristics such as accessory foramina and appearance have been studied in different populations by clinical radiographs (Yosue \& Brooks, 1989a, 1989b; Phillips et al., 1992a, 1992b; al-Khateeb et al., 1994; Al Jasser \& Nwoku, 1996; Olasoji et al., 2004; Laster et al., 2005; AlKhateeb et al., 2007) or collections of dried skulls (Phillips et al., 1992a, 1992b; Mbajiorgu et al., 1998; Sawyer et al., 1998; Ngeow \& Yuzawati, 2003; Souaga et al., 2004; Agthong et al., 2005; Igbigbi \& Lebona, 2005). Since the Gulf war in 1991, a dramatic increase of Iraqi population in Jordan, especially in the capital city Amman, has been noticed by the Jordanian immigration authority which reported more than half million of them entering and leaving Jordan since 1990 up to March 2007. Thus, Iraqi patients could form a considerable percentage of patients in any dental practice in Jordan given that the total population of Jordan was estimated to be about 6.5 million in 2012, of those 2.2 million are in Amman. The aim of the present study was to study the panoramic vertical position, appearance and presence of accessory foramina of the mental foramen in Iraqi patients, and to compare our findings with published regional and international values; it has been investigated for the first time in this population.

\section{MATERIAL AND METHOD}

The same six hundred panoramic radiographs, which were used in the first part of this study (Al-Shayyab et al., 2015) and randomly selected from the over-many-year records of Iraqi patients referred to and treated in a referral dental care center in Iraq (The Martyr Adnan Kair Allah Teaching Hospital for Specialized Surgeries) and in Jordan University Hospital in Amman, the capital city of Jordan where most Iraqis in Jordan are present, were the sample of part 2 of this study. The radiographic system and criteria used and exposure time for all chosen radiographs were different between the two centers. However, their viewing qualities were regarded to be optimal and deemed of a good diagnostic quality. The 518 panoramic radiographs were the final number of radiographs included in the present study after excluding 82 radiographs due to the following exclusion criteria:

\section{Patients aged less than 18 years.}

2. The presence of a radiolucent lesion or periodontal lesions, or a missing or an impacted tooth, or a crowding and spacing anywhere in the area extending from the lower right first molar to the lower left first molar.

3. Patient with history of orthodontic treatment of lower arch crowding and spacing.

4. Poor film quality.

A data collection form was designed and used to record the superior-inferior position, the appearance and accessory foramina on radiographs which were already scanned on the computer. This was done in standard viewing conditions such as adjusting the brightness and contrast of the computer's screen in a dark room to make radiographs appear clearer, and by two observers (maxillofacial senior residents). Some differences was found between the two observers and resolved by agreement with the opinion of the maxillofacial radiology consultant in Jordan University Hospital.

\section{Superior-inferior position of the mental foramen. A ho-} rizontal imaginary line representing the level of apices of the two mandibular premolar teeth was drawn on each side utilizing the drawing ruler of the software. Using the same definitions found in the literature (Al-Khateeb et al., 2007), the superior-inferior position of mental foramen was recorded in relation to this imaginary line, as follows:

1. Above: Where the imaginary line is located superior to the level of the apices.

2. Below: Where the imaginary line is located inferior to the level of the apices. 
3. At: Where the imaginary line is located at the level of the apices.

Radiographic appearance of the mental foramen. Using the same definitions found in the literature (Robinson et al.; Al-Khateeb et al., 2007), radiographic appearance was recorded as below, by using the drawing ruler of the software to outline the external circumference of each mandibular and mental canal:

1. Continuous: Where there is continuation between the mental and mandibular canals.

2. Separated: Where there is distinct separation of the mental foramen from the mandibular canal.

3. Diffuse: Where there is indistinct margin of the mental foramen.

4. Unidentified: When the foramen cannot be identified.

Accessory foramina. Accessory foramina was also investigated and when multiple foramina were present, the uppermost one that is closest to the inferior dental canal was recorded as the main foramen (Yosue \& Brooks, 1989a).

Statistical analysis. SPSS version 17.0 (SPSS Inc., Chicago, IL, USA) statistical software program was used to undertake the statistical analysis. Frequency distributions and cross tabulation were obtained, and chisquare test was used to perform analyses of the mental foramina's superior-inferior positions, appearance, accessory foramina and symmetry according to patients' age and sex. P-value of $<0.05$ was considered as significant.

\section{RESULTS}

The included 518 panoramic radiographs were analyzed on both sides, and were 257 for males and 261 for females with a 1:1.02 female-to-male ratio. The mean age of the cases presenting the analyzed panoramic radiographs was 46.5 years, the minimum age was 18 years, and the maximum age was $79 \mathrm{y}$ with a standard deviation of 13.8 years. Tables I and II detail the vertical location and various appearances of the mental foramen, and the presence of the accessory mental foramen.

Vertical (superior-inferior) position. The most common $(80.5 \%)$ vertical position for the mental foramen in this Iraqi sample was located below the level of the apices of mandibular premolars (Fig. 1), and was not different between right and left sides (Table I), and among males and females (Table II). Age advancement was noticed to position the mental foramen in more inferior locations (Fig. 2).

In 414 cases $(79.9 \%)$, the mental foramina superioinferiorly were symmetrically located (Fig. 3) and the remainder 104 cases $(20.1 \%$ ) were asymmetrical (Fig. 1). This superioinferior positional symmetry was found to be more prevalent in males $(83.7 \%)$ than females $(76.3$ $\%)$, and the difference was found statistically significant $(\mathrm{P}=0.035)$ (Table III). When sexes were pooled, this type of symmetry was found to be apparently more frequent in the older age group (>40 years; $90.6 \%$ ) than the younger one (11-40 years; $64.5 \%)$, and this difference was statistically significant $(\mathrm{P}=0.000)$ (Table III).

The appearance of mental foramen. The most common (71\%) appearance of the mental foramen in this Iraqi sample was continuous type (Fig. 3), and was not different between right and left sides (Table I), and among males and females (Table II). Age advancement was noticed to provide more continuous appearance of the mental foramen (Fig. 4).

In 434 cases $(83.8 \%)$, the mental foramen in both sides appeared symmetrical (Fig. 3) and the remainder 84 cases $(16.2 \%)$ were asymmetrical (Fig. 1). The frequency of symmetrical appearance of mental foramen was found to be slightly different between sexes in favor of females (males, $83.3 \%$; females, $84.3 \%$ ), and this difference was no significant $(\mathrm{P}=0.752)$ (Table III). When sexes were pooled, this type of symmetry was found to be more prevalent in the younger age group (11-40 years; $88.2 \%$ ) than the older one ( $>40$ years; $80.8 \%)$, and this difference was statistically significant $(\mathrm{P}=0.025)$ (Table III).

The presence of the accessory mental foramen. Out of 518 cases, the accessory mental foramen (Fig. 1: left side) was recorded in $7.3 \%(\mathrm{n}=38)$ (Table IV); $6.8 \%(n=35)$ in one side and $0.6 \%(n=3)$ in both sides. The later figure (number of cases with bilateral presence of accessory foramina) is to be doubled when considering right and left sides of all cases (i.e. 41 accessory foramina ( $4 \%$ ) out of 1036 sides) as shown in Tables I and II. The presence of the accessory mental foramen was slightly different between males and females, right and left sides, and young and old age groups; in favor of males (Table II), of the young age group, and of the right side, respectively (Table I). However, sex and age differences in the presence of the accessory mental foramen were not statistically significant (Table IV). 


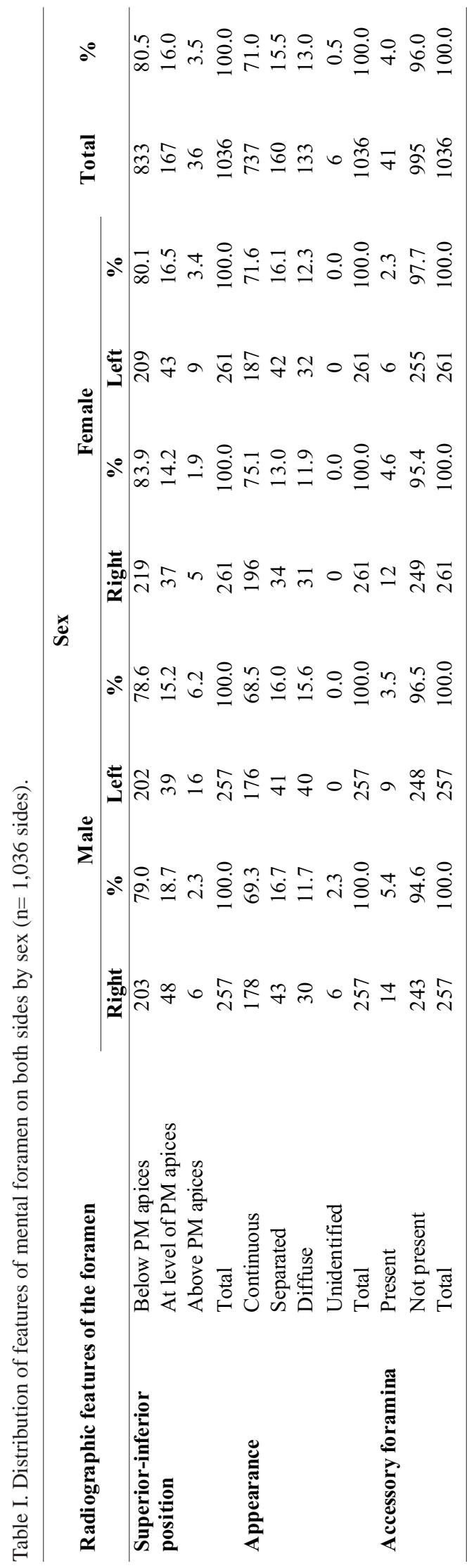

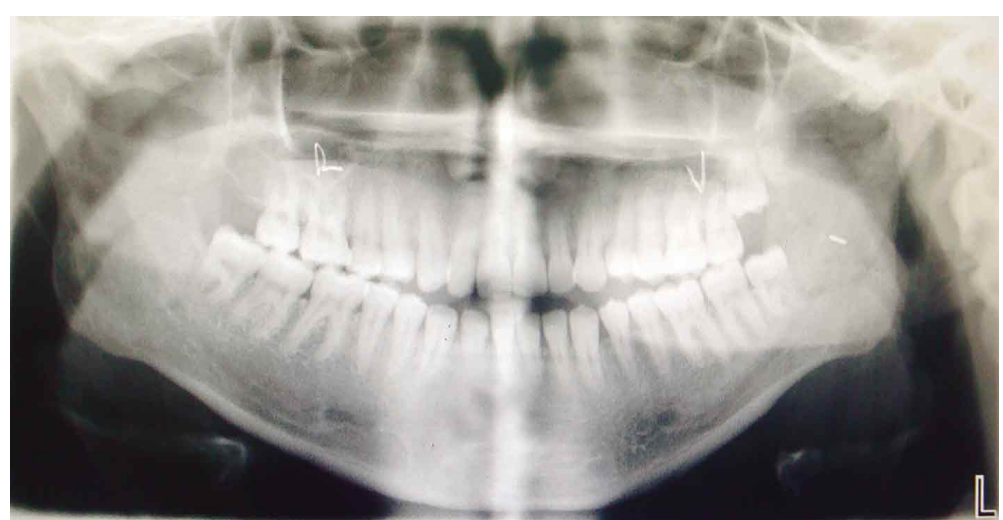

Fig. 1. A panoramic radiograph showing asymmetric superior-inferior position and appearance of mental foramina, and accessory foramen on the left side.

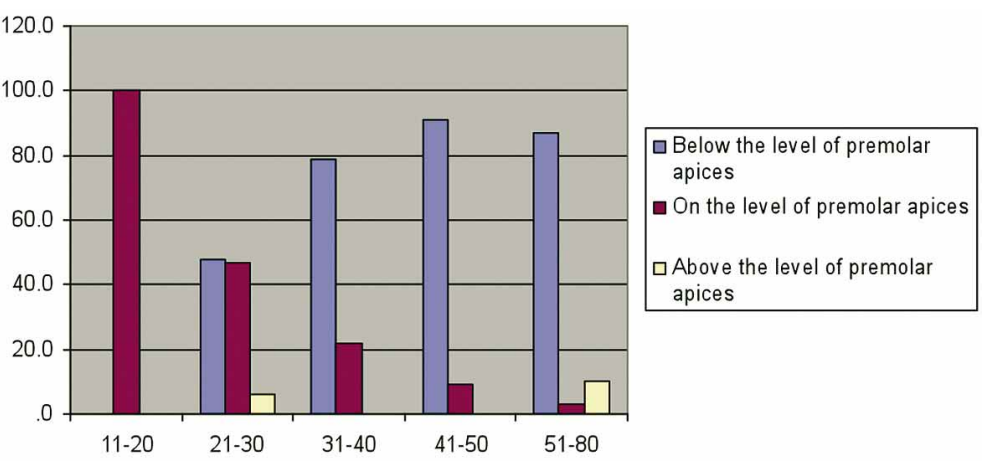

Fig. 2. A clustered graph showing the effect of advancing age on the superiorinferior location of the mental foramen ( $\mathrm{n}=1,036$ cases).

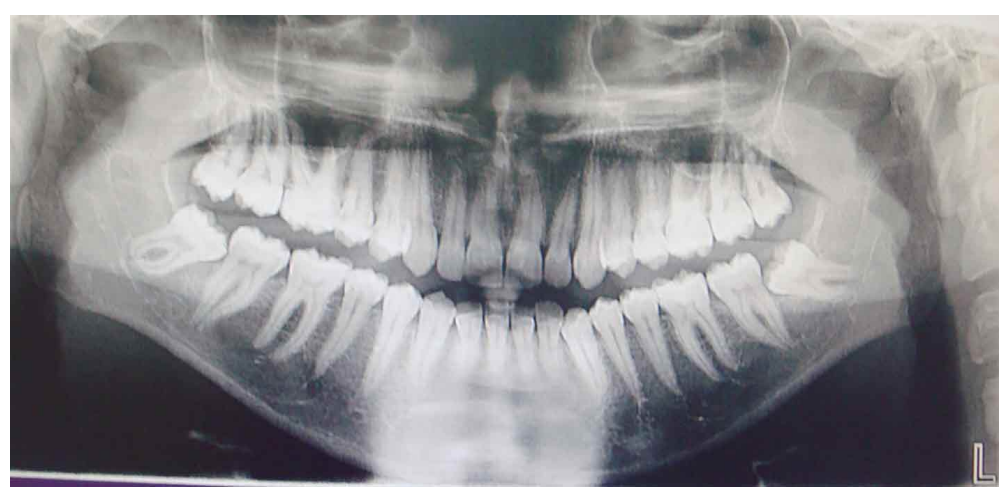

Fig. 3. A panoramic radiograph showing the mental foramen symmetrically appeared, as continuous type, and located just below the apical level of mandibular premolar teeth. 
AL-SHAYYAB, M. H.; ALSOLEIHAT, F.; DAR-ODEH, N. S.; RYALAT, S. \& BAQAIN, Z. H. The mental foramen II: Radiographic study of the superior-inferior position, appearance and accessory foramina in Iraqi population. Int. J. Morphol., 34(1):310-319, 2016.

Table II. Frequency of features of mental foramen (by sex) as seen in the present study ( $\mathrm{n}=1,036$ sides).

\begin{tabular}{|c|c|c|c|c|c|c|c|}
\hline \multirow{2}{*}{\multicolumn{2}{|c|}{ Radiographic features of the foramen }} & \multicolumn{4}{|c|}{ Sex } & \multirow{2}{*}{ Total } & \multirow{2}{*}{$\%$} \\
\hline & & Male & $\%$ & Female & $\%$ & & \\
\hline \multirow{4}{*}{$\begin{array}{l}\text { Superior-inferior } \\
\text { position }\end{array}$} & Below PM apices & 405 & 79.0 & 428 & 82.0 & 833 & 80.5 \\
\hline & At level of PM apices & 87 & 17.0 & 80 & 15.0 & 167 & 16.0 \\
\hline & Above PM apices & 22 & 4.0 & 14 & 3.0 & 36 & 3.5 \\
\hline & Total & 514 & 100.0 & 522 & 100.0 & 1036 & 100.0 \\
\hline \multirow[t]{5}{*}{ Appearance } & Continuous & 374 & 72.0 & 363 & 70.0 & 737 & 71.0 \\
\hline & Separated & 77 & 15.0 & 83 & 16.0 & 160 & 15.5 \\
\hline & Diffuse & 61 & 12.0 & 72 & 14.0 & 133 & 13.0 \\
\hline & Unidentified & 6 & 1.0 & 0 & 0.0 & 6 & 0.5 \\
\hline & Total & 514 & 100.0 & 522 & 100.0 & 1036 & 100.0 \\
\hline \multirow[t]{3}{*}{ Accessory foramina } & Present & 23 & 4.5 & 18 & 3.5 & 41 & 4.0 \\
\hline & Not present & 481 & 95.5 & 504 & 96.5 & 995 & 96.0 \\
\hline & Total & 514 & 100.0 & 522 & 100.0 & 1036 & 100.0 \\
\hline
\end{tabular}

$\mathrm{PM}=$ premolars.

Table III. Superior-inferior position and appearance of mental foramen by sex and symmetry ( $\mathrm{n}=518$ cases).

\begin{tabular}{|c|c|c|c|c|c|c|c|}
\hline & & & Symmetrical & $\%$ & Asymmetrical & $\%$ & $\mathrm{P}$ \\
\hline \multirow{6}{*}{$\begin{array}{l}\text { Sex } \\
\text { difference }\end{array}$} & \multirow{2}{*}{$\begin{array}{l}\text { Superior-inferior } \\
\text { position }\end{array}$} & Male & 215 & 51.9 & 42 & 40.4 & \multirow[t]{3}{*}{$0.035^{*}$} \\
\hline & & Female & 199 & 48.1 & 62 & 59.6 & \\
\hline & \multirow{4}{*}{ Appearance } & Total & 414 & 100.0 & 104 & 100.0 & \\
\hline & & Male & 214 & 49.3 & 43 & 51.2 & \multirow[t]{3}{*}{0.752} \\
\hline & & Female & 220 & 50.7 & 41 & 48.8 & \\
\hline & & Total & 434 & 100.0 & 84 & 100.0 & \\
\hline \multirow[t]{6}{*}{ Age groups } & Superior-inferior & $11-40$ & 136 & 32.9 & 75 & 72.1 & \multirow[t]{3}{*}{$0.000^{*}$} \\
\hline & \multirow[t]{2}{*}{ Position } & $>40$ & 278 & 67.1 & 29 & 27.9 & \\
\hline & & Total & 414 & 100.0 & 104 & 100.0 & \\
\hline & \multirow[t]{3}{*}{ Appearance } & $11-40$ & 186 & 42.9 & 25 & 29.8 & \multirow[t]{3}{*}{$0.025^{*}$} \\
\hline & & $>40$ & 248 & 57.1 & 59 & 70.2 & \\
\hline & & Total & 434 & 100.0 & 84 & 100 & \\
\hline
\end{tabular}

$\mathrm{P}=\mathrm{P}$ value of Chi-square test; $*=$ Statistically significant at the 0.05 probability level.

\section{DISCUSSION}

Knowledge concerning the exact vertical location and appearance of the mental foramen is of great clinical importance. It would lead to an accurate local anesthetic technique needed in many dental procedures and would protect the mental neurovascular bundle in different oral surgical procedures involving the mental area. Additionally, good interpretation of anatomical landmarks in oral pathology and forensics can be aided (Neo, 1989). For all of the above mentioned reasons, the vertical location and other characteristics of the mental foramen have been studied utilizing panoramic radiographs or dry skulls. Although studies reported a strong correlation and insignificant differences between measurements using comparative studies on dry skulls and those using radiographs (Yosue \& Brooks, 1989a; Phillips et al., 1990;
Al Jasser \& Nwoku, 1998), a cautious use of panoramic radiographs in reporting absolute measurements or relative comparisons has been advised (Laster et al.).

In this study, panoramic radiographs were used among other extra and intra-oral plane films to study some of the anatomic characteristics of mental foramen in this selected Iraqi sample. It is the radiograph that provides the wide field of mandible view which would consequently allow for more accurate interpretation of the mental foramen in both the horizontal and vertical dimensions (Yosue \& Brooks, 1989b; Phillips et al., 1992b). Similarly, our exclusion criteria aimed to avoid any factor that may affect accurate determination of the location or appearance of mental foramen such as periodontal lesions or history of 
Table IV. The incidence of accessory mental foramina by sex and age groups ( $\mathrm{n}=518$ cases).

\begin{tabular}{|c|c|c|c|c|c|c|c|c|}
\hline & & \multicolumn{4}{|c|}{ Accessory mental foramina } & \multirow{2}{*}{ Total } & \multirow[b]{2}{*}{$\%$} & \multirow[b]{2}{*}{$\mathbf{P}$} \\
\hline & & Absent & $\%$ & Present & $\%$ & & & \\
\hline \multirow[t]{3}{*}{ Sex } & Male & 237 & 49.4 & 20 & 52.6 & 257 & 49.6 & 0.699 \\
\hline & Female & 243 & 50.6 & 18 & 47.4 & 261 & 50.4 & \\
\hline & Total & 480 & 100.0 & 38 & 100.0 & 518 & 100.0 & \\
\hline \multirow[t]{3}{*}{ Age groups } & $11-40$ & 195 & 40.6 & 16 & 42.1 & 211 & 40.7 & 0.858 \\
\hline & $>40$ & 285 & 59.4 & 22 & 57.9 & 307 & 59.3 & \\
\hline & Total & 480 & 100.0 & 38 & 100.0 & 518 & 100.0 & \\
\hline
\end{tabular}

$\mathrm{P}=\mathrm{P}$ value of Chi-square test.

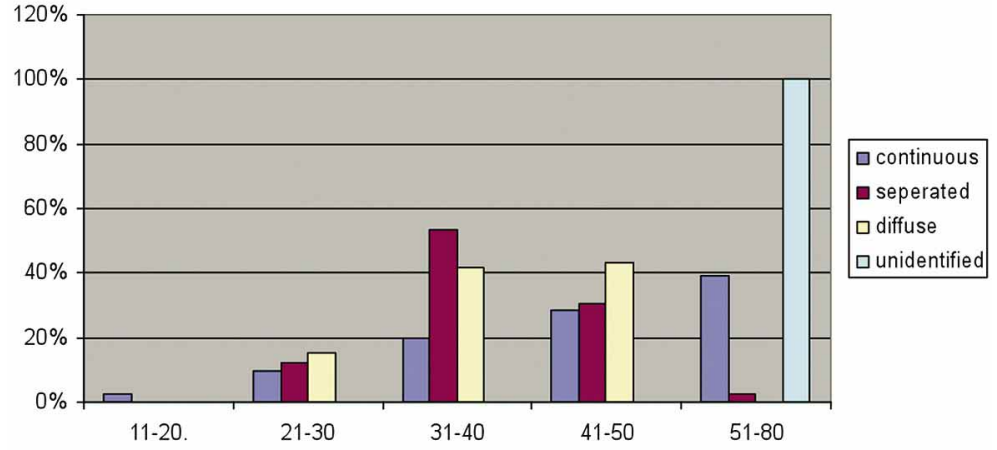

Fig. 4. A clustered graph showing the effect of advancing age on the appearance of the mental foramen $(n=1,036$ cases $)$.

orthodontic treatment which could lead to tooth migration. Poor film quality could also provide inaccurate or distorted appearance of the foramen. In the same way, only patients over the age of 18 yeras were included because we needed patients with completed skeletal growth.

Studies reported in the literature concerning the superior-inferior localization of the mental foramen have been used two different methods namely by relating the foramen to adjacent teeth or to the mandibular body. Relating the mental foramen position to the teeth is more popular in all over the world (Phillips et al., 1990, 1992a, 1992b; Al Jasser \& Nwoku, 1998; Ngeow \& Yuzawati; Olasoji et al.; AlKhateeb et al., 2007) and more convenient clinically (Green) but may be influenced by congenital or environmental factors such as race, diet, and age. These factors could have their detrimental effects on teeth alignment (i.e. malocclusion) or size (i.e. mesiodistal width). The other method is more reliable as it relates the foramen to specific points and ratios on the mandible (Laster et al.; Apinhasmit et al., 2006). However, this method is more time-consuming which is not convenient for busy clinicians.

Different superior-inferior positions and appearances of mental foramen have recently been reported to be existed between population of different or even of the same geography (Ari et al.). Further, variable superior inferior position of the mental foramen was previously reported (Yosue \& Brooks, 1989a; Phillips et al., 1990, 1992a; al-Khateeb et al., 1994; Al Jasser \& Nwoku, 1998; Mbajiorgu et al.; Olasoji et al.; Al-Khateeb et al., 2007). This variability was partly related to variable length of roots among some population samples or, but with a more consensus, to the age of patients. This later contributing factor possesses a kind of consensus from the point of view of functional and developmental facts (Kjaer, 1989; Al-Khateeb et al., 2007); the mental foramen is closer to the alveolar margin in children, half way between the alveolar and inferior margins of the mandible in adolescents and young adults, and closer to the lower margin of the mandible in dentate adults. However, these locations would be more superior in edentulous patients of the same age group where the alveolar crest shifts downwards closer to the mental foramen as a result of teeth loss. This later change in the position could provide an explanation of a burning sensation under complete dentures reported sometimes by patients. This especially occurs with extreme resorption of the alveolar bone where the mental foramen and the adjacent part of the mandibular canal would be closer to the denture fitting surface.

In this study, the superior-inferior position of the mental foramen was most commonly (80.5\%) situated below the level of the apices of mandibular premolars. Therefore, more than $80 \%$ success rate of the mental or incisive nerve block could be expected if the needle insertion point is placed just below the estimated position of the apices of mandibular premolars. Additionally, we have found that this most frequent superiorinferior position was not different between right and left sides, and among males and females. However, Age advancement located the mental foramen in more inferior positions. This later finding supports the view that variability in superior-inferior position of the mental foramen could be related to age changes. In the same way, the abovementioned results found in this study support the findings 
in previous studies from various countries and population samples (Yosue \& Brooks, 1989a, 1989b; Phillips et al., 1990, 1992a; Al-Khateeb et al., 1994; Al Jasser \& Nwoku, 1998; Mbajiorgu et al.; Al-Khateeb et al., 2007).

We have found that the position of the mental foramen was asymmetrical superioinferiorly in more than $20 \%$ of the cases. This figure of frequency of asymmetry is higher than that reported in Jordan (Al-Khateeb et al., 2007) where differences in their low frequencies of asymmetry between age groups and their statistical significance were not investigated. In the present Iraqi sample, the difference in the frequency of symmetry in the location of mental foramen was found to be statistically significant between sexes in favor of males, and between old and young age groups in favor of the older one. This agrees with previous studies on other populations (Al-Khateeb et al., 2007) where females recorded more asymmetrical superior-inferior position than males but contrasts with other studies (al-Khateeb et al., 1994) where males recorded more asymmetrical positions. The latter inconsistent result with the present study could be interpreted by the possibility of existence of geographic variation in the degree of sexual dimorphism of the symmetry of vertical location of the mental foramen.

In the present study, we observed a continuous appearance of the mental foramen in $71 \%$ of the cases and separated-appearance in $15.5 \%$. These figures are very close to those reported in some regional countries (Al-Khateeb et al., 2007) and agree with results reported on some populations in other parts of the world (Yosue \& Brooks, 1989a, 1989b). Additionally, we have found that this most frequent appearance was not different between right and left sides, and among males and females. However, Age advancement was noticed to provide more continuous appearance of the mental foramen. These results found in this study concerning side, sex and age differences were not investigated in most of the previous studies from different countries and populations (Yosue \& Brooks, 1989a; Phillips et al., 1990, 1992a; al-Khateeb et al., 1994; Al Jasser \& Nwoku, 1998; Mbajiorgu et al.; Olasoji et al.; Al-Khateeb et al., 2007). However, some of these studies (Al-Khateeb et al., 2007) showed that the most frequent appearance of the mental foramen (continuous) was slightly more common in males than in females which disagrees with our findings. On this regard, it is important to mention that the type of appearance (continuous, separated, diffuse, or unidentified) of the mental foramen was attributed by some (Yosue \& Brooks, 1989b) to the effect of possible technical conditions of the X-ray machine such as changes in exposure conditions. This later factor was argued (Al-Khateeb et al., 2007) to be impossible to evaluate in any retrospective study, which is the case of the present study.
This study found that the appearance of the mental foramen was asymmetrical in more than $16 \%$ of the cases. This rate of asymmetry is lower than that reported in Jordan (Al-Khateeb et al., 2007) where differences in their frequencies of asymmetry between age groups and their statistical significance were not investigated. However, they only reported higher frequency of asymmetry in appearance of mental foramen in males more than females. Our frequency of symmetry in the appearance of mental foramen was found to have statistically significant difference only between old and young age groups; where younger ages recorded more symmetrical appearance than the older ones.

The formation of the mental foramen is completed at the twelfth week of gestation and then followed by separation of the mental nerve into several fasciculi at the intended site. The formation of the accessory mental foramen was attributed by some authors to the occurrence of earlier separation of the mental nerve (Naitoh et al., 2009). Additionally, variations in the incidence of accessory mental foramen between ethnic groups are present (Toh et al., 1992; Sawyer et al.). In the present study, we observed accessory mental foramina in $7.3 \%$ of the cases. This figure is lower than that recently reported in some regional countries such as Jordan and on some populations from other parts of the world such as Melanesians (Sawyer et al.). However, it is higher than that reported in some regional countries such as Egyptians and on some populations from other parts of the world such as the French, Euro-Americans, Afro-Americans, Greeks, Russians and Hungarians (Mbajiorgu et al.). Studies on the Japanese population showed a prevalence of $6.7-12.5 \%$ (Toh et al.). The relatively higher incidence of accessory foramina amongst Iraqis and Jordanians than Afro-Americans undermines some reports stating that "non-Caucasians may have a higher incidence of accessory mental foramen than Caucasians" (Balcioglu \& Kocaelli, 2009).

The present study found that the differences in the incidence of the accessory mental foramen between males and females, and young and old age groups were not statistically significant which agrees with previous studies (Toh et al.; Naitoh et al.).

In this regard, it is important to mention that the use of the panoramic radiograph could be subjected to biased radiological interpretation as a result of possible low image quality, low magnification, and distortion. These later problems could lead to difficult or inaccurate identification of accessory mental foramina. This may indicate the utilization of computed tomography which is 
not applicable in this retrospective study. Consequently, a-well-visualized mandibular canal has to be guaranteed in future studies using only a panoramic radiograph rather than a CT scan. This can be achieved by $5^{\circ}$ downward movement of the patient's head with reference to the Frankfort horizontal reference bar of the machine, as suggested by Dharmar (1997).

Generally, the developmental and functional facts are likely to explain the variability and asymmetry in the vertical position, the appearance of mental foramen and accessory foramina. The mandible from developmental and functional point of views consists of several skeletal subunits; a primary neural subunit and secondary functional subunits (Sperber, 2001). Regarding the asymmetry of the mental foramen position, it is attributed to different functional secondary subunits such as the alveolar, coronoid, angular, condylar process, and chin. These secondary functional subunits are attached to the nearly symmetric primary neural subunit which is a representation of the bone surrounding the mandibular nerve or the primitive mandible. This primitive mandible is formed in the first branchial arch as the first osteogenic center of the mandibular body that arises lateral to the mandibular cartilage and to the mandibular nerve, and rapidly forms a groove that surrounds the nerve (Captier et al., 2006).

Finally, although research results and, functional and developmental facts may explain the variability and asymmetry in the superior-inferior position and appearance of mental foramen, the reason of this variability and asymmetry between people of different races, geographies, ages and sexes has probably not clearly been explained yet. Additionally, the study is not without limitations. It was a cross-sectional, epidemiologic retrospective study, and we selected only one area in Iraq due to limitation of time, funds and communication with Iraqi universities and hospitals. The small sample size was an additional limitation. Therefore, we feel that broad generalizations of the findings are not possible, and further study incorporating a nationally representative sample is needed to confirm the results.

In conclusion, the most common vertical location and appearance of the mental foramen on panoramic radiographs in this group of Iraqis being below the two premolars, and of continuous type, respectively. This is consistent with the results of previous studies in other populations. The mental foramen has usually symmetrical vertical location and appearance on both sides. Accessory mental foramina were recorded in a percentage lower than that recently reported in some regional countries such as Jordan.

\section{ACKNOWLEDGEMENTS}

We would like to thank Dr. Abeer Hadidi, the maxillofacial radiology consultant in Jordan University Hospital for helping us in the observation of the panoramic radiographs.

AL-SHAYYAB, M. H.; ALSOLEIHAT, F.; DAR-ODEH, N. S.; RYALAT, S. \& BAQAIN, Z. H. El foramen mental II: Estudio radiográfico de la posición superior-inferior, aspecto y forámenes accesorios de una población iraquí. Int. J. Morphol., 34(1):310-319, 2016.

RESUMEN: La información precisa acerca de la localización vertical, apariencia del foramen mental y la presencia de forámenes accesorios, puede tener importancia clínica, como la reducción de las complicaciones que pueden ocurrir durante muchos procedimientos quirúrgicos orales relacionados con el mentón. Las variaciones geográficas fueron reportadas en estas variables. El objetivo fue evaluar las variables anteriormente mencionadas en una muestra iraquí. Fueron evaluadas 518 radiografías panorámicas de una muestra aleatoria de Irak (257 varones, 261 mujeres, edad media = 46,5 años) con respecto a las variables antes mencionadas, así como la simetría del foramen con respecto a estas variables. El área por debajo de los ápices de los premolares mandibulares y el tipo continuo, fueron la localización vertical y apariencia del foramen mental más frecuentes, respectivamente. La edad avanzada se asoció con un aumento en la frecuencia de posicionamiento más inferior y de apariencia continua. La localización vertical y la apariencia fueron asimétricas en 16,2 $\%$ y $20,1 \%$ de los casos, respectivamente. La simetría en la localización vertical fue estadísticamente significativa entre sexos (p= 0,035), y entre jóvenes y viejos $(\mathrm{P}=0,000)$. La simetría en apariencia sólo fue estadísticamente significativa $(\mathrm{p}=0,025)$ entre los dos grupos de edad. Se registró presencia de forámenes accesorios en un 7,3 \% de los casos. La localización vertical del foramen mental más común en las radiografías panorámicas de este grupo están por debajo de los ápices de los premolares mandibulares, y respecto a la apariencia, el tipo continuo fue el más común. Esto está en coherencia con los resultados de estudios anteriores en otras poblaciones. Los forámenes mentales tienen una localización vertical y apariencia que suelen ser simétricas. Los forámenes accesorios se registran en un porcentaje inferior al informado recientemente en algunos países de la región.

PALABRAS CLAVE: Foramen mental; Radiografías panorámicas; Variación geográfica; Población iraquí. 


\section{REFERENCES}

Agthong, S.; Huanmanop, T. \& Chentanez, V. Anatomical variations of the supraorbital, infraorbital, and mental foramina related to gender and side. J. Oral Maxillofac. Surg., 63(6):800-4, 2005.

Al Jasser, N. M. \& Nwoku, A. L. Radiographic study of the mental foramen in Saudi females. Saudi Med. J., 17:471-4, 1996.

al Jasser, N. M. \& Nwoku, A. L. Radiographic study of the mental foramen in a selected Saudi population. Dentomaxillofac. Radiol., 27(6):341-3, 1998.

al-Khateeb, T. L.; Odukoya, O. \& el-Hadidy, M. A. Panoramic radiographic study of mental foramen locations in Saudi Arabians. Afr. Dent. J., 8:16-9, 1994.

Al-Khateeb, T.; Al-Hadi Hamasha, A. \& Ababneh, K. T. Position of the mental foramen in a northern regional Jordanian population. Surg. Radiol. Anat., 29(3):231-7, 2007.

Apinhasmit, W.; Methathrathip, D.; Chompoopong, S. \& Sangvichien, S. Mental foramen in Thais: an anatomical variation related to gender and side. Surg. Radiol. Anat., 28(5):529-33, 2006.

Ari, I.; Kafa, I. M.; Basar, Z. \& Kurt, M. A. The localization and anthropometry of mental foramen on late Byzantine mandibles. Coll. Antropol., 29(1):233-6, 2005.

Al-Shayyab, M. H.; Alsoleihat, F.; Dar-Odeh, N. S.; Ryalat, S. \& Baqain, Z. H. The mental foramen I: radiographic study of the anterior-posterior position and shape in Iraqi population. Int. J. Morphol., 33(1):149-57, 2015.

Balcioglu, H. A. \& Kocaelli, H. Accessory mental foramen. $N$. Am. J. Med. Sci., 1(6):314-5, 2009.

Cagirankaya, L. B. \& Kansu, H. An accessory mental foramen: a case report. J. Contemp. Dent. Pract, 9(1):98-104, 2008.

Captier, G.; Lethuilier, J.; Oussaid, M.; Canovas, F. \& Bonnel, F. Neural symmetry and functional asymmetry of the mandible. Surg. Radiol. Anat., 28(4):379-86, 2006.

de Freitas, V.; Madeira, M. C.; Toledo Filho, J. L. \& Chagas, C. F. Absence of the mental foramen in dry human mandibles. Acta Anat. (Basel), 104(3):353-5, 1979.

Dharmar, S. Locating the mandibular canal in panoramic radiographs. Int. J. Oral Maxillofac. Implants, 12(1):113-7, 1997.

Green, R. M. The position of the mental foramen: a comparison between the southern (Hong Kong) Chinese and other ethnic and racial groups. Oral Surg. Oral Med. Oral Pathol., 63(3):287-90, 1987.
Haghanifar, S. \& Rokouei, M. Radiographic evaluation of the mental foramen in a selected Iranian population. Indian J. Dent. Res., 20(2):150-2, 2009.

Hasan, T. Characteristics of the mental foramen in different populations. Internet J. Biol. Anthropol., 4(2), 2010. Available in: https://ispub.com/IJBA/4/2/6914

Igbigbi, P. S. \& Lebona, S. The position and dimensions of the mental foramen in adult Malawian mandibles. West Afr. $J$. Med., 24(3):184-9, 2005.

Kjaer, I. Formation and early prenatal location of the human mental foramen. Scand. J. Dent. Res., 97(1):1-7, 1989.

Laster, W. S.; Ludlow, J. B.; Bailey, L. J. \& Hershey, H. G. Accuracy of measurements of mandibular anatomy and prediction of asymmetry in panoramic radiographic images. Dentomaxillofac. Radiol., 34(6):343-9, 2005.

Mbajiorgu, E. F.; Mawera, G.; Asala, S. A. \& Zivanovic, S. Position of the mental foramen in adult black Zimbabwean mandibles: a clinical anatomical study. Cent. Afr. J. Med., 44(2):24-30, 1998.

Moiseiwitsch, J. R. Position of the mental foramen in a North American, white population. Oral Surg. Oral Med. Oral Pathol. Oral Radiol. Endod., 85(4):457-60, 1998.

Naitoh, M.; Hiraiwa, Y.; Aimiya, H.; Gotoh, K. \& Ariji, E. Accessory mental foramen assessment using cone-beam computed tomography. Oral Surg. Oral Med. Oral Pathol. Oral Radiol. Endod., 107(2):289-94, 2009.

Neo, J. Position of the mental foramen in Singaporean Malays and Indians. Anesth. Prog., 36(6):276-8, 1989.

Ngeow, W. C. \& Yuzawati, Y. The location of the mental foramen in a selected Malay population. J. Oral Sci., 45(3):171-5, 2003.

Olasoji, H. O.; Tahir, A.; Ekanem, A. U. \& Abubakar, A. A. Radiographic and anatomic locations of mental foramen in northern Nigerian adults. Niger. Postgrad. Med. J., 11(3):2303, 2004 .

Phillips, J. L.; Weller, R. N. \& Kulid, J. C. The mental foramen: 1. Size, orientation, and positional relationship to the mandibular second premolar. J. Endod., 16(5):221-3, 1990.

Phillips, J. L.; Weller, R. N. \& Kulild, J. C. The mental foramen: 2. Radiographic position in relation to the mandibular second premolar. J. Endod., 18(6):271-4, 1992a.

Phillips, J. L.; Weller, R. N. \& Kulild, J. C. The mental foramen: 3 . Size and position on panoramic radiographs. $J$. Endod., 18(8):383-6, 1992b. 
AL-SHAYYAB, M. H.; ALSOLEIHAT, F.; DAR-ODEH, N. S.; RYALAT, S. \& BAQAIN, Z. H. The mental foramen II: Radiographic study of the superior-inferior position, appearance and accessory foramina in Iraqi population. Int. J. Morphol., 34(1):310-319, 2016.

Robinson, P. D.; McDonald, F. \& Pitt Ford, T. R. Local Anaesthesia in Dentistry. Oxford, Wright, 2000.

Santini, A. \& Land, M. A comparison of the position of the mental foramen in Chinese and British mandibles. Acta Anat. (Basel), 137(3):208-12, 1990.

Sawyer, D. R.; Kiely, M. L. \& Pyle, M. A. The frequency of accessory mental foramina in four ethnic groups. Arch. Oral Biol., 43(5):417-20, 1998.

Souaga, K.; Adou, A. \& Angoh, Y. Topographical and morphological study of the mandibular foramen in black Africans from the Ivory Coast. Odontostomatol. Trop., 27(105):17-21, 2004.

Sperber, G. H. Craniofacial Development. London, B. C. Decker, 2001.

Toh, H.; Kodama, J.; Yanagisako, M. \& Ohmori, T. Anatomical study of the accessory mental foramen and the distribution of its nerve. Okajimas Folia Anat. Jpn., 69(2-3):85-8, 1992.

Williams, P. L. \& Bannister, L. H. J. Gray's Anatomy: The Anatomical Basis of Medicine and Surgery. $38^{\text {th }}$ ed. New York, Churchill Livingstone, 1995.

Yosue, T. \& Brooks, S. L. The appearance of mental foramina on panoramic radiographs. I. Evaluation of patients. Oral Surg. Oral Med. Oral Pathol., 68(3):360-4, 1989a.

Yosue, T. \& Brooks, S. L. The appearance of mental foramina on panoramic and periapical radiographs. II. Experimental evaluation. Oral Surg. Oral Med. Oral Pathol., 68(4):48892, 1989b.
Correspondence to:

Mohammad H. Al-Shayyab, DDS, MSc, MFD RCS (Ire), FFD

RCS (Ire).

Assistant Professor in Oral and Maxillofacial Surgery

Faculty of Dentistry

The University of Jordan

11942 Amman

JORDAN

Tel: 00962795061513

Email: mshayyab@hotmail.com

Received: 25-09-2015

Accepted: 20-10-2015 